\title{
CARACTERIZAÇÃo DE DEPÓSITO TECNOGÊNICO NO MÉDIO CURSO DO RIBEIRÃO QUATI, LONDRINA-PR
}

\author{
Edmiler José da Silva $^{(\mathrm{a})}$, Gilnei Machado ${ }^{(\mathrm{b})}$, Rafael Dantas ${ }^{(\mathrm{c})}$ \\ (a) Departamento de Geociências/ Universidade Estadual de londrina, Email: edmiler.js @ hotmail.com \\ (b) Departamento de Geociências/ Universidade Estadual de londrina, Email: gilmachad@ gmail.com \\ (c) Departamento de Geociências/ Universidade Estadual de londrina, Email: raffaeldantas@gmail.com
}

\section{Eixo: SISTEMAS GEOMORFOLÓGICOS: ESTRUTURA, DINÂMICAS E PROCESSOS}

\begin{abstract}
Resumo
Este trabalho visa entender o processo de ocupação da bacia hidrográfica do ribeirão Quati, em Londrina-PR, e sua relação com a formação de depósitos tecnogênicos ao longo de seu médio e baixo curso. Em campo, pôde-se identificar doze depósitos tecnogênicos, porém, em apenas um deles foi feita a coleta para a amostragem, este, situado no médio curso do ribeirão. Para a coleta foi utilizado cano de PVC de $100 \mathrm{~mm}$ de diâmetro por $40 \mathrm{~cm}$ de comprimento. Em laboratório, pôde-se identificar a influência antrópica em cada amostra por meio das análises quali-quatitativas. Os resultados mostraram que a maior parte do material constituinte da amostra é de origem tecnogênica sendo classificado quanto a sua composição como úrbico, ou seja, apresenta grande quantidade de materiais como vidro, tijolo, pedra brita, asfalto, entre outros.
\end{abstract}

Palavras -chave: Depósitos tecnogênicos. Ribeirão Quati. Londrina-PR

\begin{abstract}
This work aims to understand the process of occupation of the Quati river basin in Londrina-PR, and its relation with the formation of technogenic deposits throughout its medium and low course. In the field, it was possible to identify twelve technogenic deposits, however, in only one of them was collected for sampling, this one, located in the middle course of the creek. For the collection PVC pipe of $100 \mathrm{~mm}$ in diameter by $40 \mathrm{~cm}$ in length was used. In the laboratory, it was possible to identify the anthropic influence in each sample by means of qualitative-quantitative analyzes. The results showed that most of the constituent material in the sample is of technogenic origin and is classified as an argic composition, that is, it presents a great amount of materials such as glass, brick, stone, asphalt, among others.
\end{abstract}

Key words: Tecnogenic deposits. Quati River. Londrina-PR

\section{Introdução}

As alterações do meio físico-ambiental são fruto das mudanças na relação entre sociedade-natureza, que, com a evolução das técnicas ao longo do tempo passou a ter um caráter cada vez mais exploratório. Estas transformações ambientais são facilmente observadas em grandes cidades onde as paisagens estão em constantes transformações. 
No âmbito da geologia e geomorfologia as transformações do meio natural pelo homem inserem-se em um novo tempo geológico: o Quinário ou Tecnógeno. De acordo com os defenssores desta proposta, a ação humana sobre o relevo terrestre tem-lhe concedido o status de agente geológico/geomorfológico.

Para Ter-Stepaniam (1988) o período Quinário ou Tecnógeno se inicia há 10.000 anos e é marcado pela Revolução Neolítica. Segundo este autor, anteriormente ao período Holoceno o homem se estabelece como ser biológico (superior aos animais) e até mesmo como ser social, porém, isto não contribui para considerá-lo como um agente nocivo aos processos naturais.

Anteriormente ao Holoceno, as atividades humanas eram irrisórias, porém, com o advento do referido período a ação antrópica sobre o relevo se difunde. Isto permitiu a gradual descaracterização do Quaternário, e, ao mesmo tempo, o estabelecimento do período Quinário ou Tecnógeno, sendo assim, o Holoceno pode ser considerado como um período de transição entre o Quaternário e o Quinário ou Tecnógeno (TER-STEPANIAN, 1988).

Como resultado da ação geológica/geomorfológica do homem sobre o relevo, temos a formação de depósitos tecnogênicos. De acordo com Bertê (2001) apud Korb (2006) os depósitos tecnogênicos são:

O testemunho material da atividade humana que, ao se apropriar da natureza através de suas relações de produção e do emprego de uma técnica que reflete um momento histórico específico do seu nível de desenvolvimento, acaba por produzir modificações na fisiografia e fisiologia das paisagens. (BERTÊ, 2001 apud KORB 2006 p.54).

Utilizando a temática dos depósitos tecnogênicos, busca-se neste trabalho, entender a relação sociedadenatureza ao longo da ocupação da bacia hidrográfica do ribeirão Quati, em Londrina-PR.

A ciadade de Londrina-PR foi fundada em 1929 sob a influência da expanção cafeeira ao norte do Paraná. Seguindo esta conjuntura histórica-econômica, já na década de 1930 nota-se as primeiras ocupações na bacia hidrográfica do ribeirão Quati, na qual prevalecia a produção cafeeira, porém, também dividia espaço com o cultivo de cítricos e outros (CUNHA, 1996).

Ainda na década de 1930 surgiram os primeiros parcelamentos urbanos, situados na vertente direita da bacia, área que abarca o centro da cidade de Londrina. Nas décadas que se sucederam houve uma grande mudança no uso da terra, pois a área urbana foi ganhando espaço sobre a cultura agrícola, e até mesmo pastoril, que se instalou nesta área ao longo do tempo. Já na década de 1960 a vertente direita da bacia do ribeirão Quati estava com seu processo de urbanização praticamente consolidado (CUNHA, 1966).

Com a efetivação urbana da vertente direita, observa-se que os loteamentos das décadas posteiroes são direcionados à vertente esquerda. Atualmente toda a área da bacia hidrográfica do ribeirão Quati se 


\section{OS DESAFIOS DA GEOGRAFIA FÍSICA NA FRONTEIRA DO CONHECIMENTO \\ Instituto de Geociências - Unicamp \\ Campinas - SP \\ 28 de Junho à 02 de Julho de 2017}

encontra em elevado estágio de urbanização, sendo as excessões algumas áreas entre o médio e baixo curso entre a Av. Dez de Dezembro e o Conjunto Mister Thomas (FIGURA 01).

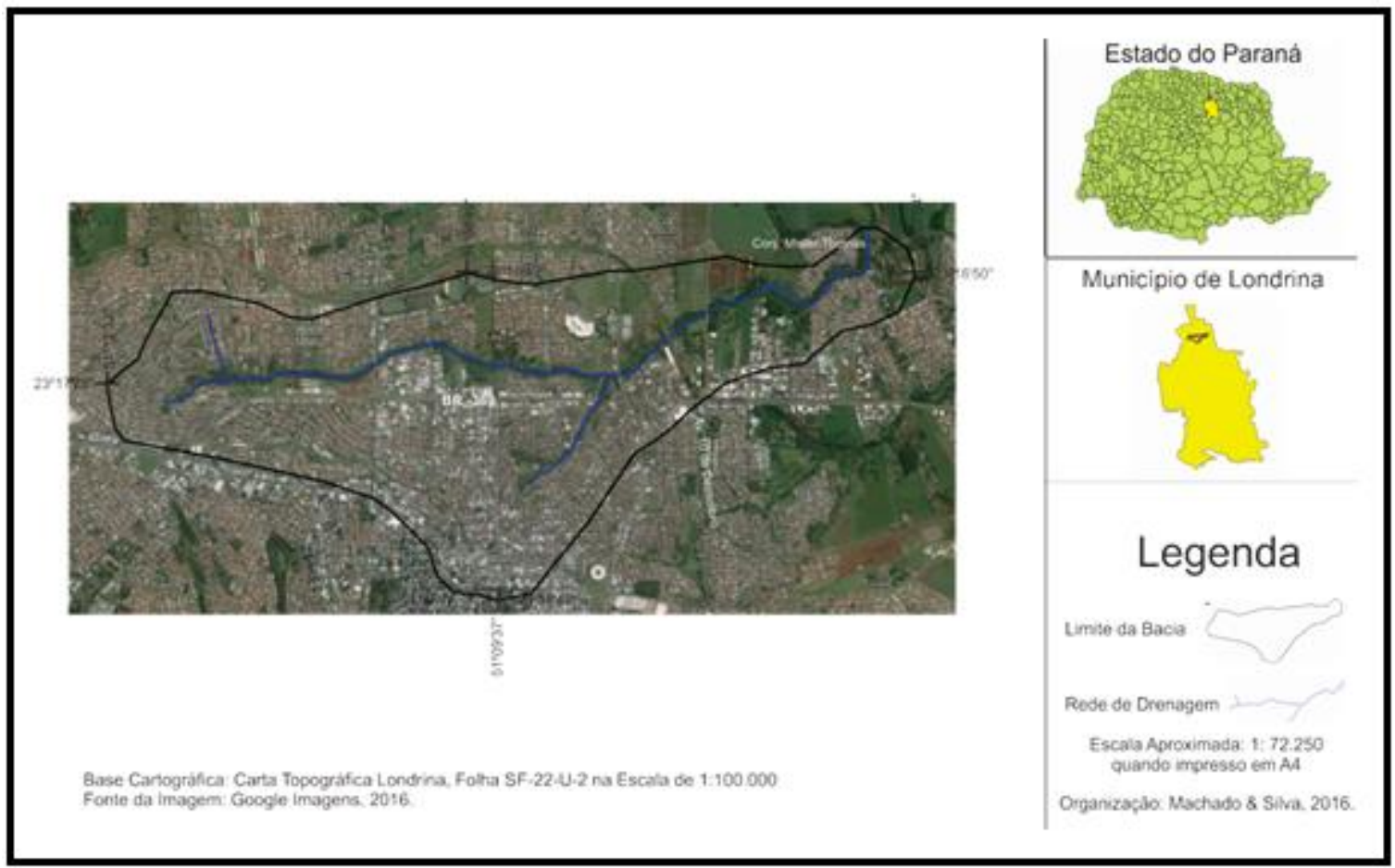

Figura 01: Urbanização da Bacia Hidrográfica do Ribeirão Quati - Londrina/PR.

Fonte: Google Imagens (2016).

Org: Machado e Silva (2016).

Durante o processo de ocupação e mudanças no uso da terra na bacia hidrográfica do ribeirão Quati, a relação sociedade-natureza ocorreu de modo predatório, com a geração de processos erosivos, desencadeando a formação de depósitos tecnogênicos no curso deste ribeirão.

Dessa forma, partindo da análise das alterações na paisagem da bacia hidrográfica do ribeirão Quati pelas mudanças no uso da terra o longo de sua ocupação, e, os processos erosivos gerados ao longo deste processo, o objetivo deste trabalho é caracterizar um desses depósitos tecnogênicos localizado no médio curso deste ribeirão.

\section{Procedimentos metodológicos}

Para a realização da presente pesquisa foram necessários: trabalhos de gabinete, trabalhos de campo e atividades laboratoriais. 
Os trabalhos de gabinete se pautaram nas leituras para o referencial teórico, no qual se abordou conceitos como: Tecnógeno, Processos erosivos, e ainda, o histórico físico-ambiental da bacia hidrográfica em questão. Ainda em gabinete, foi elaborado o mapa de localização da área, o qual foi processado no software QGIS 2.1.4, e o perfil transversal da área de estudo, para o qual utilizou-se o software Google Earth.

Em campo, foi possível analisar os aspectos sociais e ambientais que envolvem a bacia hidrográfica. Em campanhas pelo ribeirão, foram selecionados doze depósitos tecnogênicos entre o médio e o baixo curso do Quati, entretanto será discutido neste trabalho apenas um deles, localizado do médio curso do Quati.

Uma vez identificado o depósito tecnogênico, foi feita a coleta de seus dados morfométricos sendo utilizado um "sarrafo" com o qual se mediu o comprimento, largura e a profundidade do depósito. Ainda foi feito em campo, a coleta de amostra do depósito, e, para este procedimento utilizou-se canos de PVC com $100 \mathrm{~mm}$ de diâmetro por $40 \mathrm{~cm}$ de comprimento. Para auxiliar a penetração do PVC ao solo foi também utilizada uma marreta.

As atividades de laboratório foram realizadas no Laboratório de Pedologia do Departamento de Geociências da Universidade Estadual de Londrina. Nesta etapa, os materiais tecnogênicos amostrados passaram pelos procedimentos: pesagem do material úmido- secagem-peneiramento- pesagem dos fragmentos retidos em cada peneira. Estes procedimentos foram adaptações do Manual de Métodos de Análise de Solo, proposto pela EMBRAPA (1997).

Após a pesagem do material ainda úmido, a amostra foi colocada em uma estufa para secagem, à uma temperatura média de $65^{\circ} \mathrm{C}$ por $24 \mathrm{~h}$. Em seguida a amostra seca foi colocada em um agitador de partículas no qual se utilizou sete peneiras, de granulometrias que variam entre 19,1 a <0,5 mm. Os materiais retidos em cada peneira foram analisados quali-quantitativamente. A análise qualitativa foi feita através do tipo de material tecnogênicos encontrado, já a análise quantitativa se pautou no cálculo percentual de materiais de origem antrópica de cada fragmento.

Feito as análises da amostra, as mesmas foram classificadas de acordo com a Classificação Integrada proposta por Peloggia (1999), como mostra o Quadro I. 


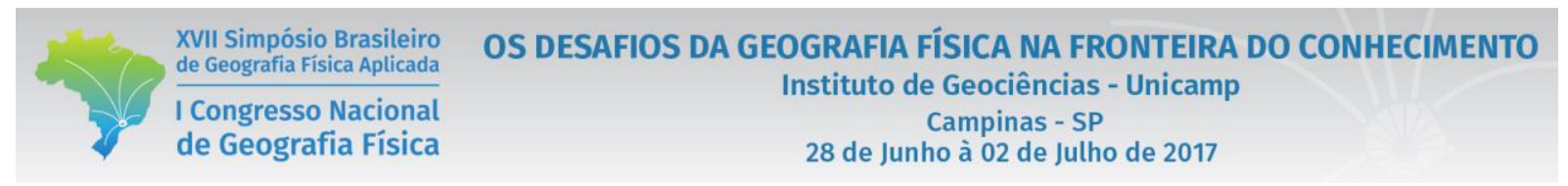

Quadro I- Classificação integrada dos depósitos tecnogênicos

\begin{tabular}{|c|c|c|c|c|c|}
\hline Parâmetro & Gênese & $\begin{array}{c}\text { Composiçã } \\
0\end{array}$ & Estrutura & $\begin{array}{l}\text { Formas de } \\
\text { Ocorrência }\end{array}$ & Ambientes \\
\hline $\begin{array}{l}\text { Depósito } \\
\text { tecnogênico } \\
\text { (d.t.) }\end{array}$ & $\begin{array}{l}1^{\text {a }} \text { ORDEM } \\
\text { Construídos } \\
\text { Induzidos } \\
\text { Modificados } \\
\text { A } \\
2^{\text {a }} \text { ORDEM } \\
\text { Retrabalhados } \\
\text { Remobilizados }\end{array}$ & $\begin{array}{l}\text { Úrbicos }{ }^{C} \\
\text { Gárbicos }{ }^{C} \\
\text { Espólicos }{ }^{C} \\
\text { Líticos } \\
\text { Sedimentares } \\
\text { Tecnogênico } \\
\text {-aluviais }{ }^{D}\end{array}$ & $\begin{array}{l}\text { Estratificados } \\
\text { Em camadas } \\
\text { Em células } \\
\text { Maciços } \\
\text { Irregulares }\end{array}$ & $\begin{array}{l}\text { Maciços } \\
\text { isolados } \\
\text { Lençóis de } \\
\text { aterramento } \\
\text { Coluviformes } \\
\text { Aluviformes }\end{array}$ & $\begin{array}{l}\text { Industriais }^{{ }^{B}} \\
\text { Mineiros }^{B} \\
\text { Urbanos }^{B} \text { e } \\
\text { peri-urbanos } \\
\text { Rurais }{ }^{B}\end{array}$ \\
\hline
\end{tabular}

Referências: (1999): A) Oliveira, 1990; B) Osovetskiy, 1996; C) Fanning \& Fanning, 1989; D) Osovetskiy, 1996 Org: Peloggia, (1999).

\section{Resultados e discussões}

A bacia hidrográfica do ribeirão Quati está localizada nas regiões norte, central e oeste de Londrina-PR. Possui uma área de $83,4 \mathrm{Km}^{2}$, tendo seu canal principal 11,2 Km de extensão e constituído pelos afluentes principais de Bom Retiro e Ibirá (FIGURA 01).

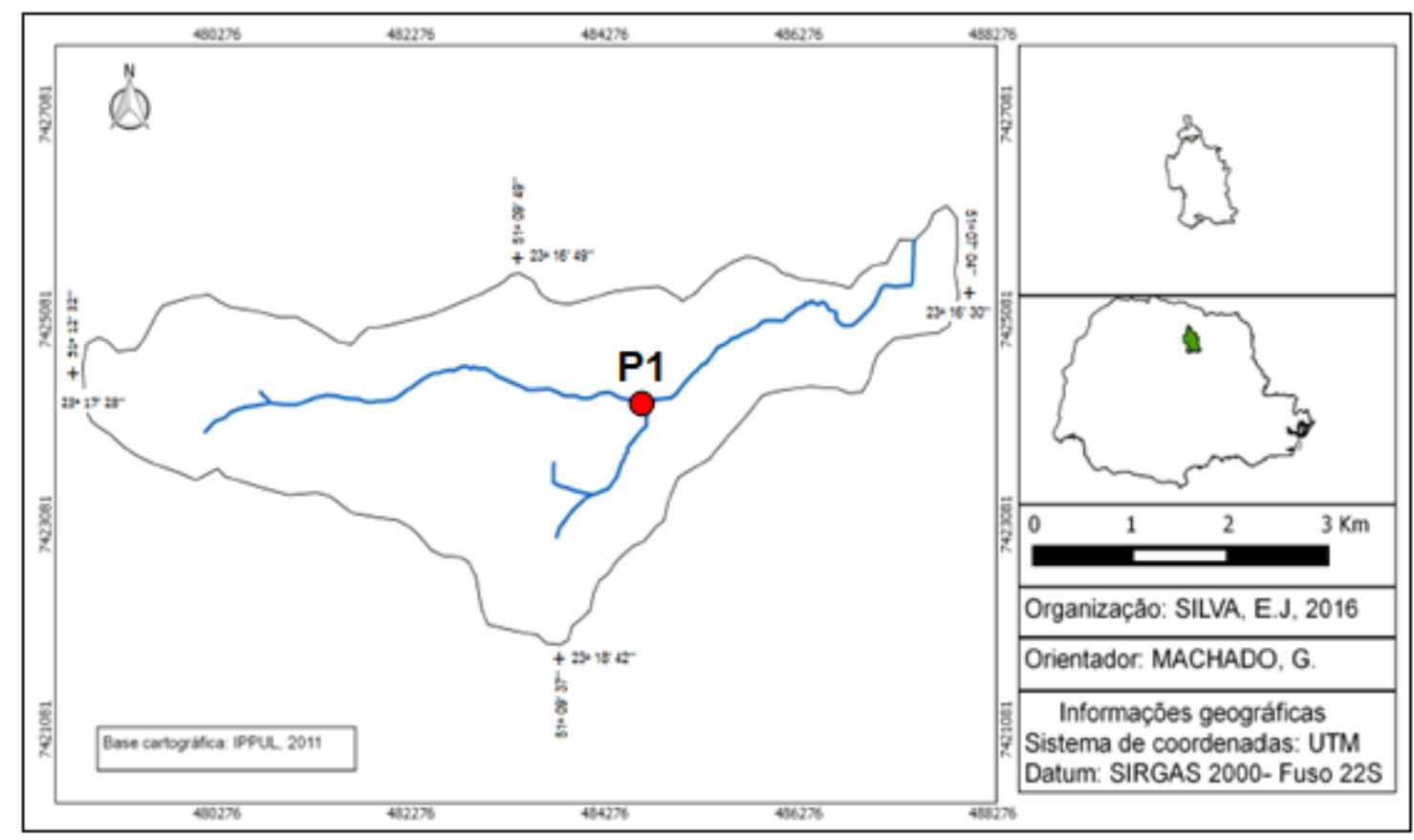

Figura 02- Área da bacia hidrográfica do ribeirão Quati e localição do Ponto do depósito 1. Fonte: Silva (2017). 
Até o meados do século XIX prevalecia na área da bacia hidrográfica do ribeirão Quati, uma densa floresta pluvial tropical, também conhecida como Ombrófila, a qual foi substituída ao longo do tempo pelas plantações de café e pastos e, posteriormente, pela urbanização.

A cultura agrícola e pastoril predominante nas décadas iniciais de ocupação da bacia do ribeirão Quati foi responsável pelos primeiros processos de degradação ambiental. A supressão da vegetação e a exposição direta do solo aos agentes intempéricos foi o principal fator responsável pelo aparecimento de processos erosivos nas vertentes da bacia.

Vicente (1989) ao estudar a qualidade ambiental da bacia, se referindo a década de 1953, salientou que neste período já eram perceptíveis feições derivadas de processos erosivos, como sulcos, ravinas e voçorocas, principalmente na vertente direita, onde se inicia o processo de urbanização da bacia.

Contudo, as mudanças ocorridas no uso do solo, do agrário para o urbano, avançaram para a vertente esquerda da bacia, a qual passou por um gradativo processo de urbanização, principalmente após a década de 1960, quando os espaços vazios da porção direita se encontravam praticamente todos ocupados. Tal processo de ocupação proporcionou a intensificação no aparecimento de feições erosivas, em ambas as vertentes.

A impermeabilização do solo como resultado da evolução da malha urbana nas décadas seguintes influenciou na diminuição de feições erosivas. Estas, por sua vez, passaram a ser mais comuns nas áreas próximas ao fundo de vale, onde a água começou a chegar com altas velocidades, conduzida por rede pluvial ou mesmo na superfície do asfalto.

As feições erosivas originadas ao longo da ocupação da bacia do ribeirão Quati: sulcos, ravinas e voçorocas, relacionados aos processos erosivos acelerados, se tornaram as principais fontes de sedimentos, os quais vêm se depositando na baixa vertente, fundo de vale e canal fluvial. Além disso, a simples exposição do terreno condiciona o carregamento das partículas do solo pelo escoamento superficial.

Os sedimentos transportados podem ser de origem natural, como partículas de solo, e também oriundos de materiais antrópicos, ligados ao uso da terra em cada período de ocupação da área. Os materiais de origem humana depositados foram os responsáveis pela formação de depósitos tecnogênicos ao longo do curso do ribeirão Quati.

Os materiais componentes destes depósitos apresentam, portanto, características naturais, sendo este o materiais como: silte, areia, argila e seixos arredondados, e também, características antrópicas, como os materiais mais grosseiros representados por seixos angulados, materiais oriundos de construção civil, entre outros. 
A seguir, será feita a análise da área e do ponto em que se localiza o depósito aqui discutido, que serão chamados de ponto e depósitos 1 .

\subsection{Análise da área e do ponto do depósito 1}

Este ponto se localiza no médio curso do ribeirão Quati, próximo da confluência com o córrego Bom Retiro e da Avenida Dez de Dezembro. Nesta área nota-se o elevado estágio de urbanização, principalmente em sua vertente direita. Verifica-se na vertente esquerda alguns vazios urbanos, entretanto, em vias de expansão pela valorização da área com a construção do Londrina Norte Shopping (Figura 02).

Os valores hipsométricos (transversal) das vertentes variam de 567 a $505 \mathrm{~m}$. Nota-se na vertente direita um declive abrupto quase no limite com o divisor de águas, resultado de cortes durante a expansão urbana nesta área.

A declividade média apresenta-se baixa, 3,9\%, sendo que no local do depósito esta chega a 6,6\%. $\mathrm{O}$ depósito se encontra a $510 \mathrm{~m}$ de altitude, ou seja, pouco acima de áreas ao seu redor, devido o afloramento de nascentes nas adjacências do local.

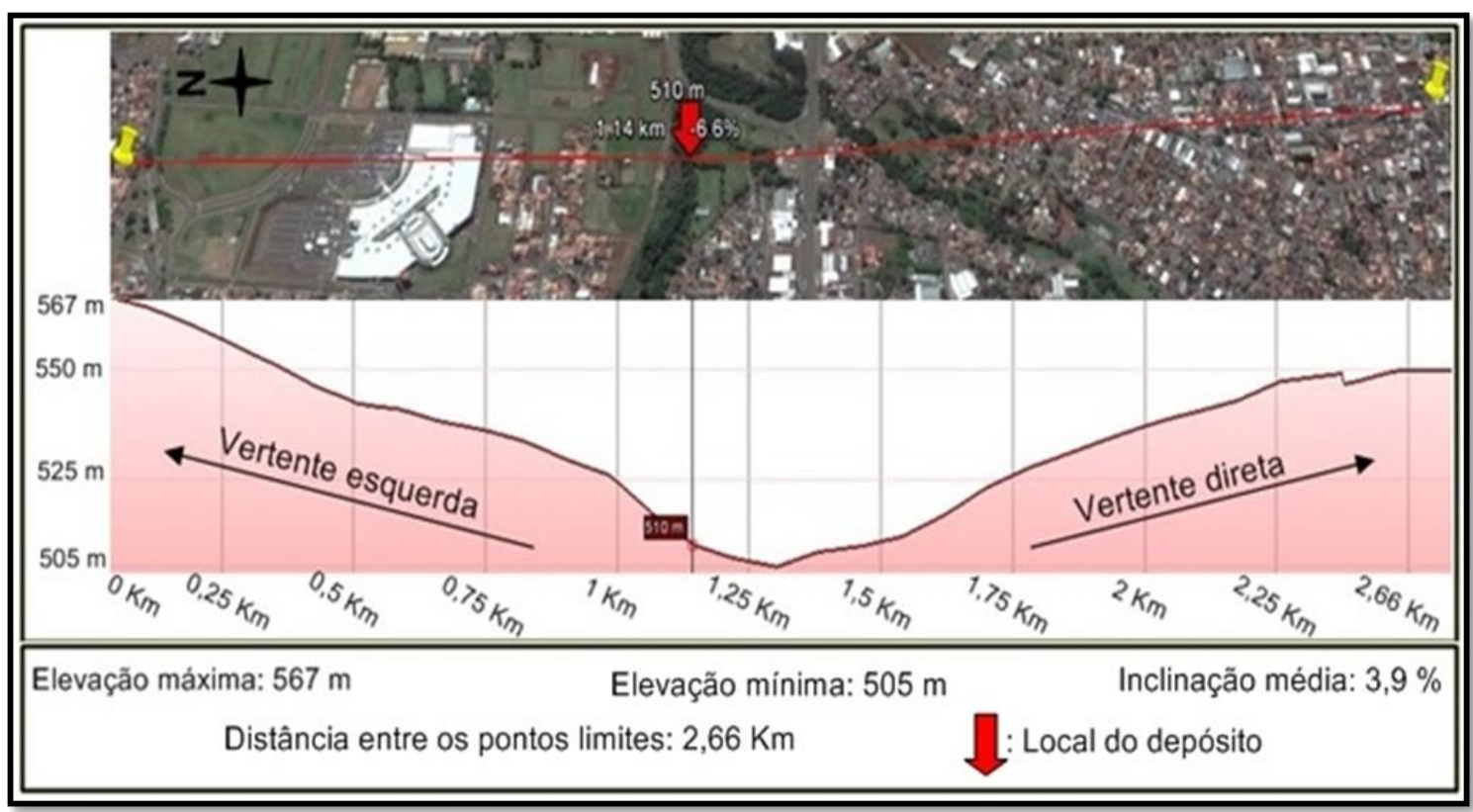

Figura 03- Área e perfil transversal referente ao ponto 1 Fonte: Google Earth (2016).

Org: Silva (2017). 
O depósito tecnogênico localizado neste ponto encontra-se na margem direita do ribeirão e apresentou 1,5 $\mathrm{m}$ de largura, $3 \mathrm{~m}$ de comprimento e $40 \mathrm{~cm}$ de profundidade. Neste ponto foram coletados $40 \mathrm{~cm}$ de amostra a qual apresentou 3,3 $\mathrm{Kg}$ após a secagem. Deste total, 2,9 $\mathrm{Kg}$ foram considerados materiais tecnogênicos, ou seja, $88 \%$ da amostra. Estes materiais foram representados por seixos utilizados na construção civil, fragmento de tijolos, vidro, pedra britada, parafuso, alumínio, fragmentos de asfalto, barra, de ferro e concreto (Figura 04).

Os materiais considerados de origem natural encontrados nesta amostra foram: silte, areia e argila, representando os materiais finos, e também, seixos resultante do trabalho do ribeirão e matéria orgânica. O peso dos sedimentos de origem natural foi de $0,4 \mathrm{Kg}$, equivalente a $12 \%$ da amostra.

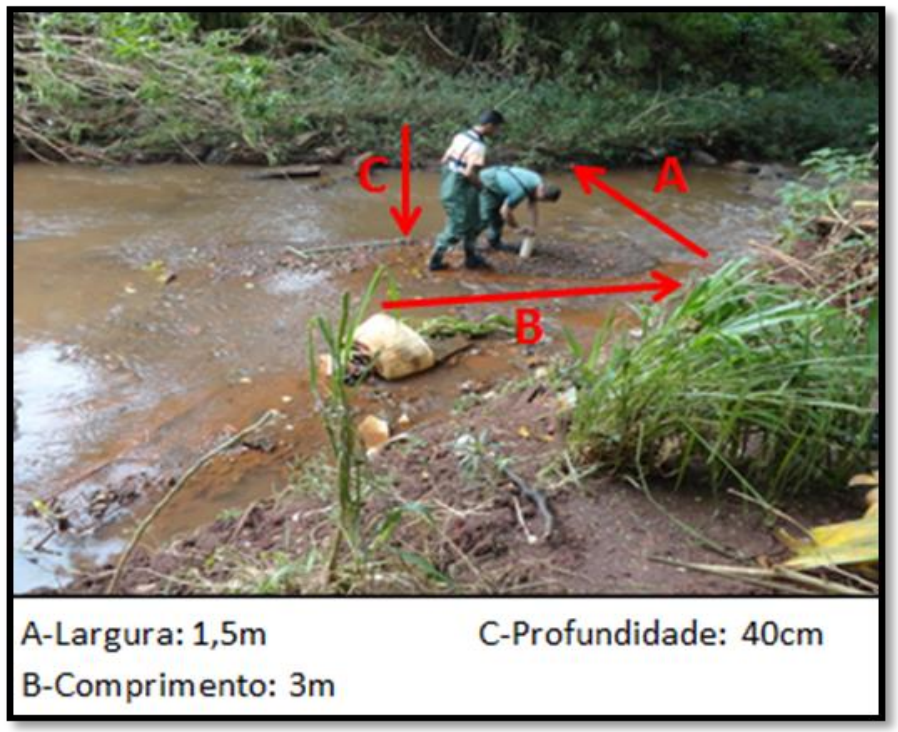

Figura 04- Ponto do depósito 1

Foto: Canezim (2016)

Org: Silva(2016) 


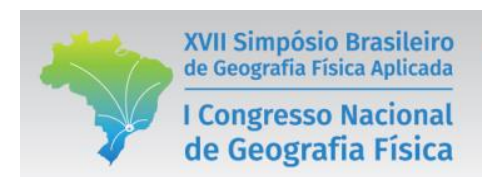

OS DESAFIOS DA GEOGRAFIA FÍSICA NA FRONTEIRA DO CONHECIMENTO
Instituto de Geociências - Unicamp

Campinas - SP

28 de Junho à 02 de Julho de 2017

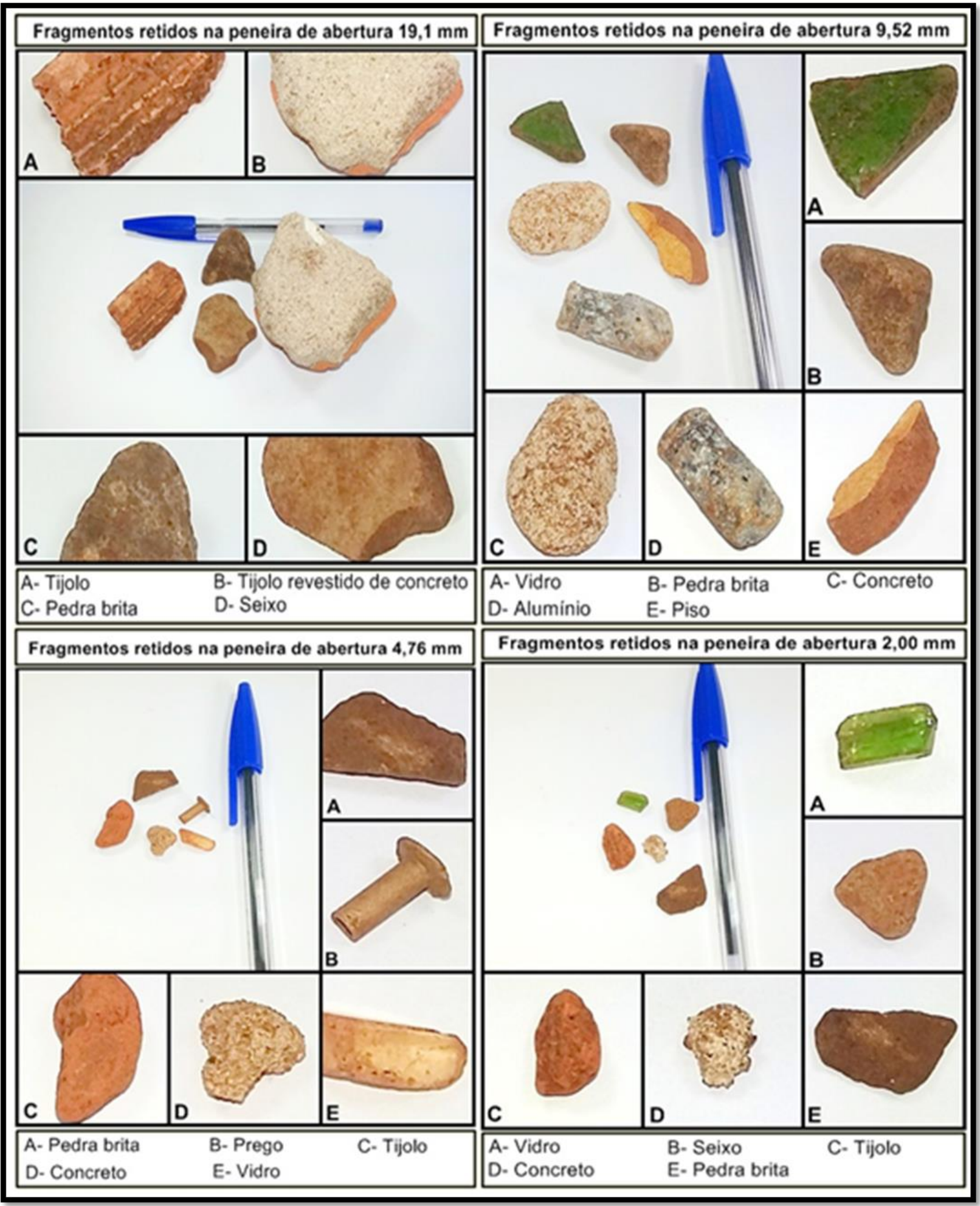

Figura 05- Materiais tecnogênicos encontrados na amostra 1.

Foto e org: Silva (2016). 


\section{Considerações finais}

Devido à consolidação urbana da vertente direita, os vazios urbanos presentes na vertente esquerda são os principais fornecedores de materiais de origem tecnogênica ao depósito analisado, com destaque para os gerados pela construção civil, dessa forma a gênese do depósito é considerada do tipo induzida.

Vale lembrar que as vertentes não são as únicas que determinam o grau de influência antrópica dos depósito, embora sejam por elas que os materiais tecnogênicos chegam até o curso do rio. O próprio trabalho do rio conduz os materiais tecnogênicos no sentido montante-jusante de seu curso, ou até mesmo os próprios depósitos, visto que eles são remobilizados. Sendo assim no tocante a forma de ocorrência este depósito pode ser classificado como aluviforme.

Por estar sob a influência direta do curso d'água, não foi possível fazer o perfil do solo, uma vez que não há uma estrutura interna definida, por isso, a estrutura deste depósito foi considerada como do tipo maciço.

Ao fazer a análise qualitativa do material tecnogênico, notou-se a predominância daqueles resultantes da construção civil, sendo considerados como úrbicos. Esta característica é típica do local em que está o ribeirão, e consequentemente, o depósito analisado: área urbana.

\section{Agradecimentos}

A CAPES- Coordenação de Aperfeiçoamento de Pessoal de Nível Superior- pelo apoio recebido por meio de concessão de bolsa para o curso de mestrado em geografia

\section{Bibliografia}

CUNHA, F. Crescimento urbano e poluição hídrica na Zona Norte de Londrina-PR. Presidente Prudente, 1996. 138f. Dissertação (Mestrado em Geografia)- Universidade Estadual de São Paulo, 1996.

EMBRAPA. Centro Nacional de Pesquisas de Solos. Sistema Brasileiro de Classificação de Solos. 2.ed. Rio de Janeiro: EMBRAPA-SPI, 2006.

KORB, C.C. Identificação de Depósitos Tecnogênicos no Reservatório Santa Bárbara, Pelotas (RS). $2006.189 f$. Dissertação (Mestrado em Geografia). Instituto de Geociências, Universidade Federal do Rio Grande do Sul. Porto Alegre, 2006.

PELOGGIA, A.U.G. Sobre a classificação, enquadramento estratigráfico e cartográfico dos solos e depósitos tecnogênicos. In: PELOGGIA, A.U.G. Manual Geotécnico 3: Estudos de Geotécnica e Geologia Urbana (I). São Paulo,1999. P. 35-50.

PREFEITURA DO MUNICÍPIO DE LONDRINA. IPPUL. Mapas temáticos: zoneamento de Londrina. Instituto de Pesquisa Planejamento Urbano de Londrina, 2001. Disponível em: www.londrina.pr.gov.br.

TER-STEPANIAN, G. 1988. Beginning of the Technogene. Bulletin I.A.G. 38: 133-142. 


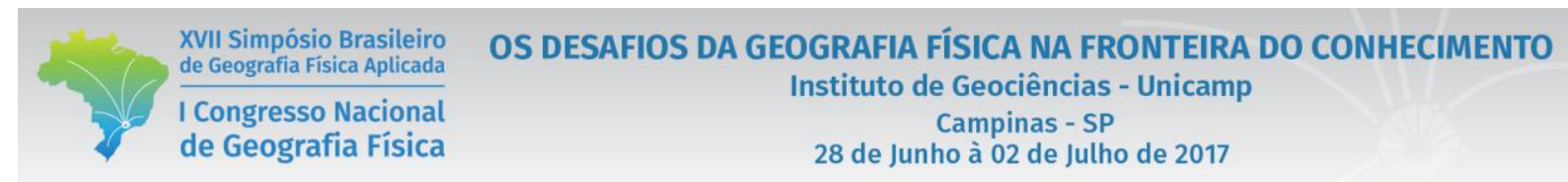

VICENTE, M. A. Diagnóstico ambiental. A bacia do ribeirão Quati. Londrina: UEL, 1989. (Monografia). Departamento de Geociências, Universidade Estadual de Londrina. 